\title{
Application of Remote Sensing Data in Lithological Discrimination of Kerdous Inlier in the Anti Atlas Belt of Morocco
}

\author{
Amine Jellouli ${ }^{\#}$, Abderrazak El Harti ${ }^{\#}$, Zakaria Adiri", El Mostafa Bachaoui ${ }^{\#}$, Abderrahmane El Ghmari ${ }^{\#}$ \\ \# Department of Earth Sciences, Sultan Moulay Slimane University, Beni Mellal, Morocco \\ E-mail: aminejellouli90@gmail.com
}

\begin{abstract}
Remote sensing data reveals a great importance for lithological mapping due to their spatial, spectral and radiometric characteristics. Lithological mapping using spatial data is a preliminary and important step to mineral mapping. In this work, several spectral and radiometric transformations methods were applied on Landsat 8 OLI data to enhance lithological units in the study area situated in the Anti Atlas belt. The methods of Optimum Index Factor (OIF), Decorrelation Stretching (DS), Principal Components Analysis (PCA) and Band Ratioing (BR) showed good results for lithological mapping in comparison with the existing geological and field investigation. An RGB color composite of OLI bands 651 was developed for mapping lithological units of the study area by fusing optimum index factor (OIF) and decorrelation stretching methods. furthermore, Band ratios derived from image spectra were applied in two RGB color composites $(7+4 / 2, \mathrm{PC} 1, \mathrm{PC} 2)$ and $(\mathrm{PC} 1,7 / 6,3 / 7)$ providing good discrimination of the lithological units. The Landsat-8 OLI data significantly provided satisfied results for lithological mapping.
\end{abstract}

Keywords — Landsat 8 OLI, OIF, Anti Atlas Belt, PCA, Lithological mapping.

\section{INTRODUCTION}

The use of remote sensing as an advanced and efficient technique has shown its advantages in several fields such as lithological and mineralogical mapping and lineament mapping [1], [2]. On the one hand, it has reduced the cost and time of field investigations and on the other hand, it offers a variety of multispectral and hyperspectral data covering a large area [3],[2],[4].

The availability of image data, with high or medium spatial and spectral resolution, opens the door to an easy and efficient identification of different geological structures such as lineaments. furthermore, the different techniques and methods of spatial imaging processing allow to extract interpretable geological information with better precision [5].

Multispectral imagery data produced by multispectral sensors such as Landsat 8 OLI, Terra ASTER, Landsat 5 TM, Sentinel-2A and Landsat 7 ETM + have shown their efficiency in mapping lithological units at different scales [2] [4], as well as hyperspectral imagery data from hyperspectral satellite and airborne sensors such as EO-1 Hyperion and AVIRIS respectively, which are used for lithological and mineralogical mapping due to their high spectral resolution allowing the identification of hydrothermal alterations minerals [3],[6],[7]. Several studies have been achieved in lithological mapping by applying different spectral and radiometric techniques and methods in order to enhance the lithological structures [8], [9]. In addition, radar remote sensing has been widely used in geological mapping as it is extremely operational in the acquisition of images day and night and even below clouds [10], [11].

Pournamdari et al (2014) demonstrated the utility of Terra ASTER and Landsat 5 TM data for lithological mapping in the Soghan ophiolotic complex in Iran. MohsenPournamdari et al (2014) used several spectral transformation methods such as band ratioing (BR), Principal Component Analysis (PCA), Correlation Coefficient (CC) and Optimum Index Factor (OIF), MohsenPournamdari et al (2014) developed a RGB band ratio 4/1, 4/5, 4/7 using the ASTER image to discriminate lithological units in ophiolitic complexes, as well as the results obtained from ASTER and TM images by applying the ACP methods., OIF and CC showed a good correlation with the pre-existing geological map. Amer et al (2010) applied Principal Component Analysis (PCA) and band ratios (BR) on Terra ASTER imagery in the central eastern Fawakhir Desert in Egypt, Thus, They presented a new method for lithological mapping in arid environments. In addition, Amer et al (2010) showed that ASTER data have important potential for mapping granitic and ophiolitic rocks by applying band ratios $(2+4) / 3,(5+7) / 6,(7+9) /$ 8. Also, a color composite of the ACP bands $(5,4,2)$ showed satisfied results to identify ophiolitic rocks 


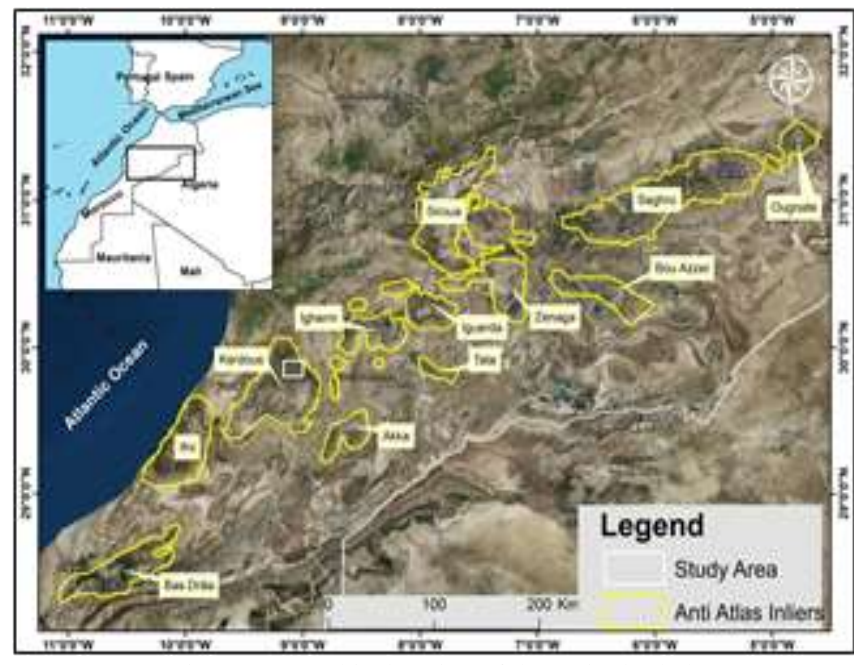

Fig. 1 Geographical setting of the anti atlas belt

\section{GEOLOGICAL SETTING OF THE STUDY AREA}

The Moroccan Anti-Atlas is a mountain belt in southwestern Morocco, oriented ENE-WSW about $800 \mathrm{~km}$ long and $200 \mathrm{~km}$ wide (Fig. 1). It is located between the central High Atlas and the Sahara desert and extending south of the High Atlas Mountains and north of the West African Craton (WAC)[12], the latter is formed during the phase of the Eburnean Orogeny which characterized the assembly of the Precambrian Anti Atlas terrains in the form of twelve inliers [13].
The Kerdous inlier belongs to the western Anti Atlas, among the inliers of the Moroccan Anti Atlas, it presents a complex precambrian basement diversified by the existence of important structural formations specifically Tanalt, Anzi and Tafraout [13].

The study area is located between latitudes $28^{\circ} 4$ '20.56" $\mathrm{N}$ and $32^{\circ} 7^{\prime} 0.38^{\prime \prime} \mathrm{N}$ and longitudes $4^{\circ} 32$ ' 34.93 " $\mathrm{W}$ and $11^{\circ} 15^{\prime} 3.93 " \mathrm{~W}$. This study area consists of breccias and volcanic rocks that break off discontinuously along Kerdous inlier boundaries of the Tanalt Formation in the Ouarzazate Group [13].

Northeast of Kerdous inlier, the Neoproterozoic quartzites of Jbel Lkest are truncated by a dip extension NE associated with conglomerates of the Tanalt Formation. Northeast ofthe study area, the lower Cambrian is represented by the sedimentary formations of dolomites and argillites of the Taroudant group (Adoudou and Iz'riyne formations). The vulcanites and ryolitic ignimbrites characterize neoproterozoic formation Ait-Baha [13]. The geological map used in this study is the Tanalt geological map (1:50 000), published in 2001 by the Ministry of Industry, Trade, Energy and Mining and is prepared by the British Geological Institute. Survey. The diversely oriented faults and fractures of the study area reflect the multiple deformation events that have affected the region through geologic time. in addition, the study area has to be considered as a promising mineral exploration zone by several research institutions by reason of geological history of the Anti Atlas belt and its mineral ore deposits abundance.

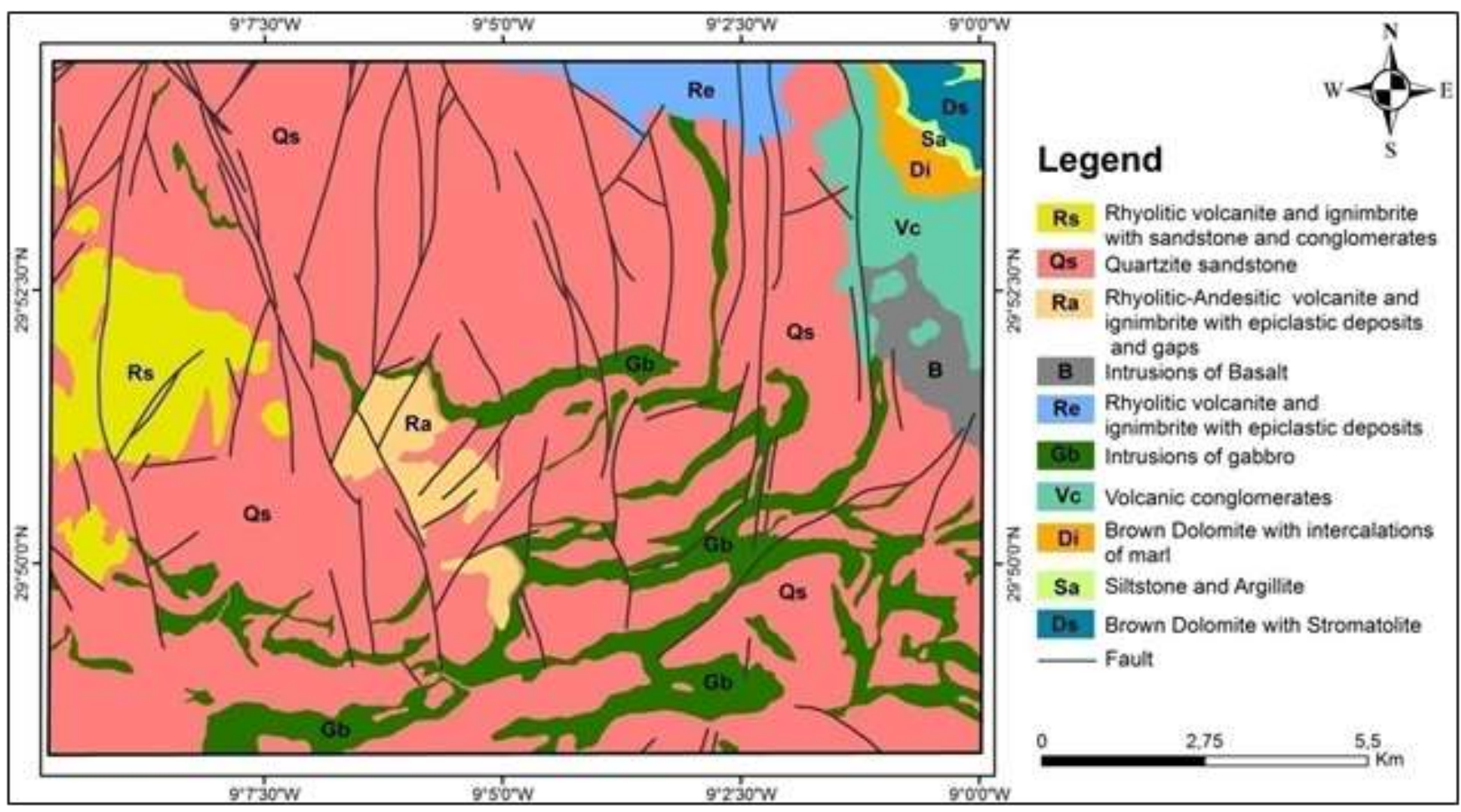

Fig. 2 Lithological map of the study area 

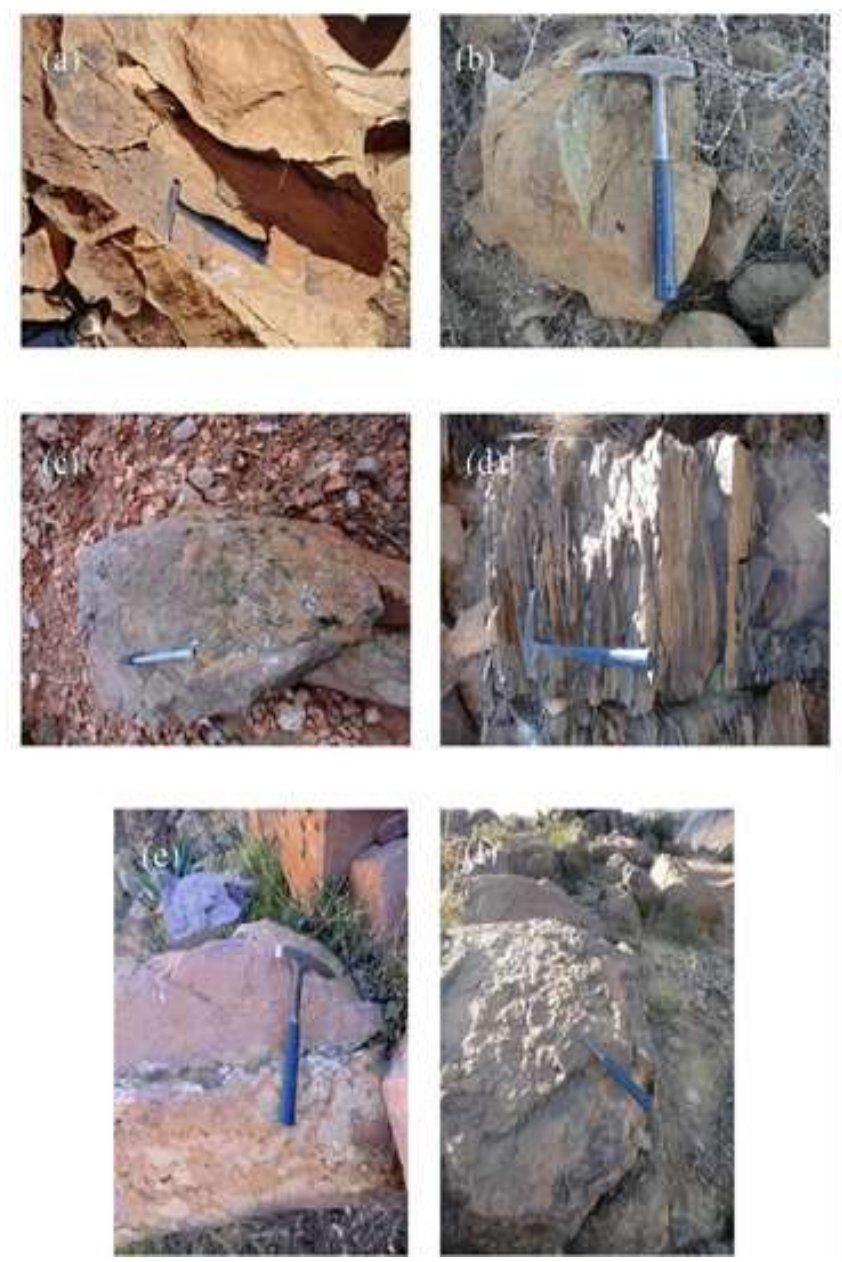

Fig. 1 Field photographs of lithological units: (a) Brown dolomite with intercalations of marl (b) Quartzite sandstone (c) Intrusions of gabbro (d) Siltstone and argillite (e) Rhyolitic volcanite and ignimbrite with epiclastic deposits (f) Volcanic conglomerates

\section{MATERIALS AND METHODS}

\section{A. Landsat 8 Oli Data}

The Landsat 8 satellite was launch on February 11, 2013 and carries both sensors, the Operational Land Imager (OLI) and Thermal Infrared Sensor (TIRS), these sensors covers the Visible and Near Infrared (VNIR), Short Wave Infrared (SWIR) and Thermal Infrared range (TIR) of the electromagnetic spectrum on 11 bands, including a deep blue coastal/aerosol band and a short-wave cirrus band [14].

Operational Land Imager (OLI) multispectral sensor collect data in a range of spectral regions through the visible and near infrared (VNIR), short wave infrared (SWIR). OLI has 9 spectral bands, including 5 VNIR between 0.43 and $0.88 \mu \mathrm{m}$ including coastal aerosol band, 3 SWIR bands between 1.57 and $2.29 \mu \mathrm{m}$ including the Cirrus band (Table I). We used the OLI level-1T (Corrected Terrain) data product from the Land Processes Distributed Active Archive Center at NASA. The Landsat 8 OLI image is radiometrically calibrated, geometrically co-registered and orthorectified. Landsat 8 OLI image scene are characterized by a high radiometric resolution (16 bits), and the scenes cover $185 \times 180 \mathrm{~km}$, available at free of charges [14].
TABLE I

CARACTERISTICS OF LANDSAT 8 OLI BANDS

\begin{tabular}{|c|c|c|c|}
\hline \multirow{10}{*}{ 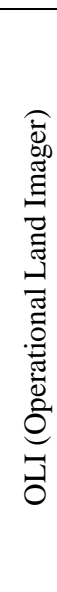 } & \multicolumn{2}{|c|}{ Spectral Band $(\mu \mathrm{m})$} & Spatial \\
\hline & 1- Coastal Aerosol & $0.43-0.45$ & 30 \\
\hline & 2- Blue & $0.45-0.51$ & 30 \\
\hline & 3- Green & $0.53-0.59$ & 30 \\
\hline & 4- Red & $0.64-0.67$ & 30 \\
\hline & 5- Near Infrared (NIR) & $0.85-0.88$ & 30 \\
\hline & 6- SWIR 1 & $1.57-1.65$ & 30 \\
\hline & 7- SWIR 2 & $2.11-2.29$ & 30 \\
\hline & 8- Panchromatic & $0.50-0.68$ & 15 \\
\hline & 9- Cirrus & $1.36-1.38$ & 30 \\
\hline
\end{tabular}

\section{B. Data Preprocessing}

The OLI Image Is Radiometrically Corrected In TOA (Top Of Atmosphere) Apparent Reflectance Image, Subsequently, It Is Corrected For Atmospheric Effects And Converted To Reflectance By Applying The Dark Object Subtraction (DOS) Algorithm [15].

\section{Data Processing}

1) Optimum Index Factor And Decorrelation Stretching The OIF method (Optimum Index Factor) is a statistical approach used to select the best color composite for the good visualization of the OLI image [16]. This method has been developed to determine the colored composition containing the maximum information and the least redundancy. This approach is used to enhance the lithological units, it was calculated by the following formula:

OIF $=\frac{\sum(\text { Standard deviation }(i, j, k)}{\sum(C C(i, j), C C(i, k), C C(k, j))}$

$\mathrm{i}, \mathrm{j}, \mathrm{k}$ are the three selected spectral bands CC: Correlation coefficient

The method of decorrelation stretching is a radiometric transformation used to decorrelate the colored composition of a multispectral image [17]. It is applied to the selected color composite of the OLI image by the OIF method in order to enhance the studied lithological units. In this work, the Optimum Index Factor method was coupled with the decorrelation stretching method in order to obtain the suitable results for lithological discrimination

2) Band Ratioing And Principal Component Analysis The band ratio method has been widely used in lithological and mineralogical mapping as it is demonstrated by several studies intended for the discrimination of lithological units [9][18]. moreover, this method has been used for the identification of different hydrothermal alteration minerals [3], [19]. This spectral transformation reduces the effect of topography and difference in brightness in a satellite image [18]. 
Principal Component Analysis (PCA) is a statistical method applied to multispectral and hyperspectral image in order to reduce the number of spectral bands containing non-redundant information [20]. It consists of transforming the set of image data with correlated variables into new bands called Principal Components (PCs). It has the advantage of compressing the information contained in the original bands, eliminating information redundancy in the image data and isolating noise, which enhances the targeted information in the image. this method is extensively applied in geological mapping and lineaments mapping as well [21].

\section{RESULTS AND DISCUSSION}

\section{A. Optimum Index Factor And Decorrelation Stretching}

The Optimum Index Factor (OIF) and Decorrelation Stretching methods are used to enhance the lithological units in the study area. The OIF index is calculated for the OLI image and three RGB color composites are chosen. the selected RGB color composite of bands 651 (fig. 4) contains the maximum of information. The tables I and II show the OIF of the three RGB color composites and correlation values of OLI image, respectively:

TABLE II

Oif VAlues Of The Three Selected RgB Color Composites

\begin{tabular}{|c|c|c|c|c|}
\hline & Blue & Green & Red & OIF value \\
\hline \multirow{4}{*}{$\begin{array}{c}\text { Color } \\
\text { Composite }\end{array}$} & band 1 & band 5 & band 6 & 71.42 \\
\cline { 2 - 5 } & band 1 & band 5 & band 7 & 71.02 \\
\cline { 2 - 5 } & band 2 & band 5 & band 7 & 69.24 \\
\hline
\end{tabular}

OLI image show that RGB color composites 651 and 751 have almost the same OIF values as a result of high correlation between bands 6 and 7 (table II). Based on the results obtained, the selected RGB color composite 651 is decorrelated by applying the Decorrelation Stretching method in order to enhance contrast and demonstrate more details (fig. 4). The RGB color composite 651 shows good discrimination of the abundant lithological units of quartzite sandstone (Qs) and intrusions of gabbro $(\mathrm{Gb})$ and are distinguished by

TABLE III

Correlation Values Of The Oli IMAge

\begin{tabular}{|c|c|c|c|c|c|c|c|}
\hline OLI bands & Band & Band & Band & Band & Band & Band & Band \\
\hline Band 1 & 1 & & & & & & \\
\hline Band 2 & 0.99 & 1 & & & & & \\
\hline Band 3 & 0.96 & 0.98 & 1 & & & & \\
\hline Band 4 & 0.93 & 0.95 & 0.98 & 1 & & & \\
\hline Band 5 & 0.74 & 0.79 & 0.85 & 0.83 & 1 & & \\
\hline Band 6 & 0.78 & 0.82 & 0.88 & 0.91 & 0.85 & 1 & \\
\hline Band 7 & 0.85 & 0.86 & 0.90 & 0.93 & 0.79 & 0.96 & 1 \\
\hline
\end{tabular}

Brown-orange and green colors respectively. The rhyolitic-andesitic volcanite and ignimbrite with epiclastic deposits and gaps ( $\mathrm{Ra}$ ) is mapped by the cyan color while rhyolitic volcanite and ignimbrite with sandstone and conglomerates (Rs) is discriminated by blue-grenat color. Brown dolomite with intercalations of marl (Di) appears by red-pink color and siltstone with argillite $(\mathrm{Sa})$ are also discriminated by pink-orange color. In addition, volcanic conglomerates unit $(\mathrm{Vc})$ is mapped by the light blue. Regarding intrusions of basalt unit (B), it appears grenat. The ryolitic volcanite and ignimbrite with epiclastic deposits $(\mathrm{Re})$ is mapped by the blue color. Finally, brown dolomite with stromatolite (Ds) appears in orange-red color.

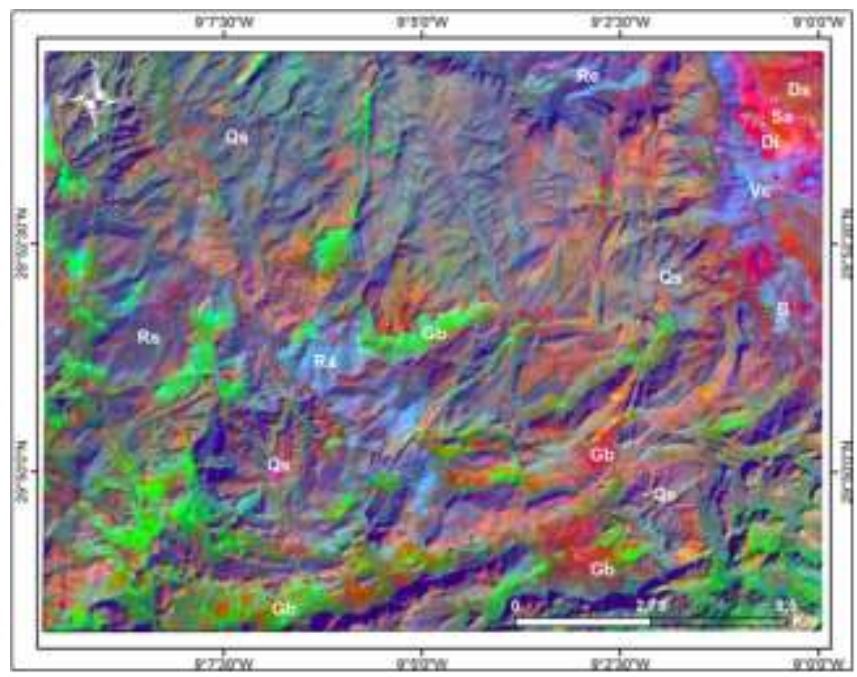

Fig. 2 Selected RGB color composite 651 of OLI image bands

\section{B. Band Ratioing And Principal Component Analysis}

Three bands ratios were derived on the basis of the corrected OLI image spectra allows identification of several lithological units of the study area, these bands ratios were selected to be combined with principal components analysis bands to reveal the best lithological discrimination. The bands ratio $(7+4 / 2)$ is allowed to discriminate brown dolomite with stromatolite (Ds), since its spectra shows high reflectance in bands 7 and 4, against absorption in band 2 . additionally, the quartzite sandstone (Qs) were detected by the ratio $(7 / 6)$ because its spectra represents high reflectance in band 7 and absorption in band $6(1.6 \mu \mathrm{m})$ at the SWIR range which refers to argillic alteration [21]. The band ratio (3/7) enhanced the lithological units, volcanic conglomerates $(\mathrm{Vc})$ and rhyolitic volcanite and ignimbrite with epiclastic deposits (Re), showing a high reflectance in band 3 and an absorption in band $7(2.20 \mu \mathrm{m})$ related to $\mathrm{Al}-\mathrm{OH}$ absorption due to clay minerals [21].

The principal component analysis (PCA) transformation has been applied to the OLI spatial subset scene of the study area. A new PCA image contains 6 new image components were generated from the original 6 bands $(\mathrm{VNIR}+\mathrm{SWIR})$ of the original OLI image. The principal component analysis transformation was applied to the 6 VNIR+SWIR bands of OLI image to collect more information which could not be extracted from the VNIR + SWIR bands of the original data. the three first components (PC1, PC2 and PC3) have $99.78 \%$ of eigenvalues 
percentage of all the bands and were fused with Band Ratios in RGB color composites to enhance lithological units of the study area. The PC1 has the highest eigenvalue. TABLE IV

Matrix Of Eigenvectors Extracted After Calculating The Pca On Oli Image

\begin{tabular}{|l|c|c|c|c|c|c|}
\hline $\begin{array}{c}\text { PCs/ } \\
\text { Bands }\end{array}$ & Band 1 & Band 2 & Band 3 & Band 4 & Band 5 & Band 6 \\
\hline PC 1 & 0.132 & 0.221 & 0.376 & 0.452 & 0.597 & 0.479 \\
\hline PC 2 & -0.010 & 0.039 & -0.074 & 0.819 & -0.147 & -0.547 \\
\hline PC 3 & 0.325 & 0.414 & 0.619 & -0.058 & -0.578 & 0.007 \\
\hline PC 4 & -0.092 & -0.192 & -0.294 & 0.342 & -0.530 & 0.684 \\
\hline PC 5 & 0.635 & 0.480 & -0.599 & -0.037 & 0.063 & 0.030 \\
\hline PC 6 & 0.681 & -0.714 & 0.148 & 0.034 & 0.027 & -0.041 \\
\hline
\end{tabular}

percentage of all the bands approximately (97\%) with all positive contributions. In table IV, the PC2 shows positive contribution at band 4 and negative contributions in bands 5 and 6 and the image enhanced well the intrusions of gabbro $(\mathrm{Gb})$ with vegetation, also, it enhanced the volcanic conglomerates ( $\mathrm{Vc}$ ). In addition, the rhyoliticandesitic volcanite and ignimbrite with epiclastic deposits and gaps (Ra)

and volcanic conglomerates $(\mathrm{Vc})$ are distinguisged in PC3 which shows positive contribution at band 3 and negative contribution in band 5. By analyzing the characteristics and rate of contributions of PC4, brown dolomite with intercalations of marl (Di) and quartzite sandstone (Qs) are detected as brightly pixilated and it shows extremely negative and positive contributions in bands 5 and 6 respectively. The silstone and argillite (Sa) can be detected as bright pixels in PC5 because of the positive contributions in bands 1 and 2 while negative contributions derived from band 3. For the remaining PC6, it had not been considered in further processing because it contain only noise and cannot provide any valuable information.

In the light of the results obtained from bands ratios and principal components analysis and after applying different combinations of bands ratios and PCA, two RGB color composite (CC) images were generated using the PC1 and PC2 outputs with the selected band ratios. In CC1 $(7+4 / 2$, PC1, PC2) (fig. 5), brown dolomite with stromatolite (Ds) is mapped by yellow-orange color, while it appears dark green in $\mathrm{CC} 2$ (PC1, 7/6, 3/7) as showen in fig. 6. The quartzite sandstone (Qs) is well distinguished by a light green color in $\mathrm{CC} 1$, while it appears green-orange in CC2. for the intrusions of gabbro unit (Gb), it is enhanced clearly in $\mathrm{CC} 2$ by pink color with vegetation in blue. The same for volcanic conglomerates $(\mathrm{Vc})$ that are mapped by pink-blue color in $\mathrm{CC} 2$.

\section{CONCLUSION}

The present work used the multispectral Landsat 8 OLI bands for mapping existing lithological units in the study area. The results of OIF and Decorrelation Stretching methods showed that the Color composites RGB of bands 6, 5 and 1 of OLI enhances well the abundant lithological units of quartzite sandstone (Qs), intrusions of gabbro $(\mathrm{Gb})$ and volcanic conglomerates $(\mathrm{Vc})$. Thus, lithological units of brown dolomite with stromatolite (Ds), brown dolomite with intercalations of marl (Di) and siltstone and argillite (Sa) were also distinguished. The developed RGB color composites $(7+4 / 2, \mathrm{PC} 1, \mathrm{PC} 2)$ and (PC1, 7/6, 3/7) showed almost the same enhanced visualization of the lithological units and are similar to the RGB color composites using OIF and Decorrelation Stretching methods. The obtained results indicate that Landsat- 8 OLI bands have great capability to extract spectral information to map lithological units for further purposes

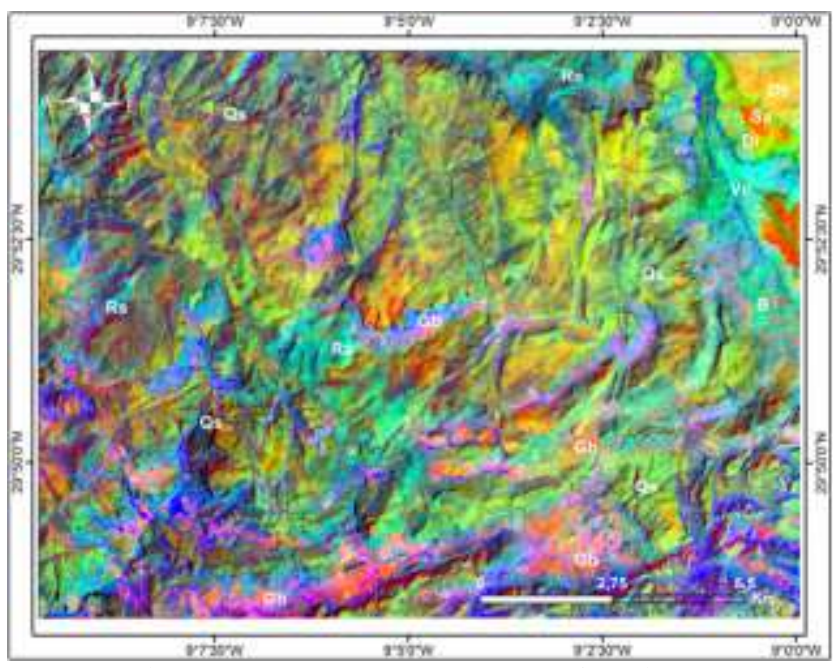

Fig. 5 RGB CC 1: $(7+4) / 2$, PC1, PC2 of OLI image

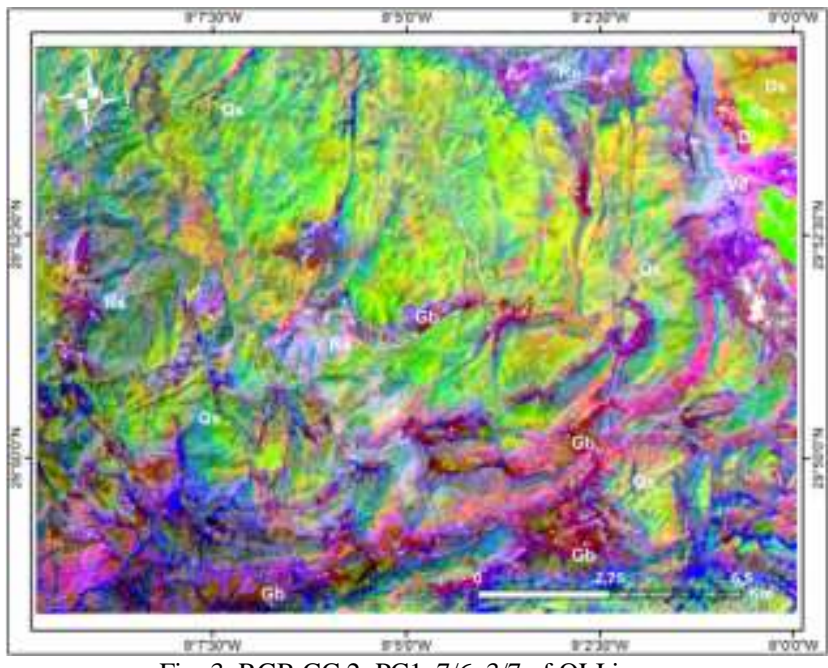

Fig. 3 RGB CC 2: PC1, 7/6, 3/7 of OLI image

\section{ACKNOWLEDGMENT}

This work was conducted as a part of a research project supported by the remote sensing and GIS team appplied for geosciences and the environment at the faculty of sciences and techniques of Beni Mellal. We are thankful to the CNRST (National Center for Scientific Technical Research) for his financial and academic support.

\section{REFERENCES}

[1] A. Guha and K. Vinod Kumar, "New ASTER derived thermal indices to delineate mineralogy of different granitoids of an Archaean Craton and analysis of their potentials with reference to Ninomiya's indices for delineating quartz and mafic minerals of 
granitoids-An analysis in Dharwar Cr," Ore Geol. Rev., vol. 74, pp. 76-87, 2016.

[2] A. B. Pour and M. Hashim, "The application of ASTER remote sensing data to porphyry copper and epithermal gold deposits," Ore Geol. Rev., vol. 44, pp. 1-9, 2012.

[3] F. A. Kruse, J. W. Boardman, and J. F. Huntington, "Comparison of Airborne Hyperspectral Data and EO-1 Hyperion for Mineral Mapping," vol. 41, no. 6, pp. 1388-1400, 2003.

[4] M. Pournamdari, M. Hashim, and A. Beiranvand, "Spectral transformation of ASTER and Landsat TM bands for lithological mapping of Soghan ophiolite complex , south Iran," Adv. Sp. Res., vol. 54, no. 4, pp. 694-709, 2014.

[5] S. Jakob, B. Bühler, R. Gloaguen, C. Breitkreuz, H. Ali, and K. El, "Journal of African Earth Sciences Remote sensing based improvement of the geological map of the Neoproterozoic Ras Gharib segment in the Eastern Desert ( NE e Egypt ) using texture features," J. African Earth Sci., vol. 111, pp. 138-147, 2015.

[6] Z. Adiri, A. El Harti, A. Jellouli, L. Maacha, M. Zouhair, and E. M. Bachaoui, "Mapping copper mineralization using EO-1 Hyperion data fusion with Landsat 8 OLI and Sentinel-2A in Moroccan AntiAtlas," Geocarto Int., vol. 0, no. 0, pp. 1-20, 2019.

[7] M. Anti-atlas et al., "Mineralogical mapping using Landsat-8 OLI , Terra ASTER and Sentinel-2A multispectral data in Sidi," J. Spat. Sci., vol. 00, no. 00, pp. 1-25, 2018

[8] W. Ge, Q. Cheng, Y. Tang, L. Jing, and C. Gao, "Lithological Classification Using Sentinel-2A Data in the Shibanjing Ophiolite Complex in Inner," 2018.

[9] H. Van Der Werff and F. Van Der Meer, "Sentinel-2A MSI and Landsat 8 OLI Provide Data Continuity for Geological Remote Sensing," no. June 2015, 2016.

[10] S. Cesar et al., "Radarsat-1 image processing for regional-scale geological mapping with mining vocation under dense vegetation and equatorial climate environment , Southwestern Cameroon," Egypt. J. Remote Sens. Sp. Sci., vol. 21, pp. S43-S54, 2018.

[11] S. K. Pal, T. J. Majumdar, and A. K. Bhattacharya, "ERS-2 SAR and IRS-1C LISS III data fusion: A PCA approach to improve remote sensing based geological interpretation," vol. 61, pp. 281297, 2007.
[12] D. Gasquet, G. Levresse, A. Cheilletz, M. R. Azizi-Samir, and A Mouttaqi, "Contribution to a geodynamic reconstruction of the Anti-Atlas (Morocco) during Pan-African times with the emphasis on inversion tectonics and metallogenic activity at the Precambrian-Cambrian transition," Precambrian Res., vol. 140, no. 3-4, pp. 157-182, 2005.

[13] A. Soulaimani, A. Essaifi, N. Youbi, and A. Hafid, "Les marqueurs structuraux et magmatiques de l'extension crustale au Protérozoïque terminal-Cambrien basal autour du massif de Kerdous (Anti-Atlas occidental, Maroc)," Comptes Rendus Geosci., vol. 336, no. 16, pp. 1433-1441, 2004.

[14] D. P. Roy et al., "Landsat-8: Science and product vision for terrestrial global change research," Remote Sens. Environ., vol. 145, pp. 154-172, 2014.

[15] Z. Zhang, G. He, and X. Wang, "A practical DOS model-based atmospheric correction algorithm," Int. J. Remote Sens., vol. 31, no. 11, pp. 2837-2852, 2010.

[16] C. P. S, B. L, and S. L. B, "Statistical Method for Selecting Landsat MSS Ratios."," J. Appl. Photogr. Eng., vol. 8, no. March, p. 23 , 1982.

[17] A. Ciampalini, F. Garfagnoli, B. Antonielli, S. Moretti, and G. Righini, "Remote sensing techniques using Landsat ETM+ applied to the detection of iron ore deposits in Western Africa," Arab. J. Geosci., vol. 6, no. 11, pp. 4529-4546, 2013.

[18] R. Amer, T. Kusky, and A. Ghulam, "Lithological mapping in the Central Eastern Desert of Egypt using ASTER data," J. African Earth Sci., vol. 56, no. 2-3, pp. 75-82, 2010.

[19] L. C. Rowan and J. C. Mars, "Lithologic mapping in the Mountain Pass , California area using Advanced Spaceborne Thermal Emission and Reflection Radiometer ( ASTER ) data," vol. 84, pp. 350-366, 2003.

[20] X. Zhang, M. Pazner, and N. Duke, "Lithologic and mineral information extraction for gold exploration using ASTER data in the south Chocolate Mountains ( California )," vol. 62, pp. 271-282, 2007.

[21] Z. Adiri, A. El Harti, A. Jellouli, L. Maacha, and E. M. Bachaoui, "Lithoogical mapping using Landsat 8 OLI and Terra ASTER multispectral data in the Bas Drâa inlier, Moroccan Anti Atlas," vol. 10, no., pp. 16005-16014, 2016. 